\title{
Teoria Econômica da Religião: Aspectos Gerais
}

\author{
Lívio Luiz Soares Oliveira Correio*
}

\section{Resumo}

Este trabalho tem o objetivo de ser uma apresentação, em linhas gerais, da Teoria Econômica da Religião. Utiliza-se como metodologia a revisão de literatura relativa a essa disciplina. Apresenta a origem e o posterior desenvolvimento da Teoria Econômica da Religião. Mostra-se a importância da religião sob a ótica da Ciência Econômica. Discute-se as diferenças entre a Teoria Econômica da Religião e a chamada Tese da Secularização, enfatizando, principalmente, a realidade empírica da persistência e da intensidade do fenômeno religioso. Por fim, são abordadas as ligações entre Teoria Econômica da Religião e a Teoria da Escolha Racional. A conclusão principal é a de que, dada a especificidade da Teoria Econômica da Religião, as pesquisas que relacionam religião e economia podem beneficiar ambas as disciplinas de diversas formas.

Palavras-chave: Religião, economia, mercado, racional.

\section{Economics Theory of Religion: Overview.}

\begin{abstract}
This work aims to present the Economics Theory of Religion. The methodology uses the literature review of this discipline. It shows the origins and subsequent development of the Economics Theory of Religion. The work explains the importance of religion from the perspective of Economics. The text discusses the differences between the Economics Theory of Religion and the so-called Secularization Thesis, emphasizing, mainly, the empirical reality of the persistence and intensity of religious phenomenon. Lastly, it addresses the connections between Economics Theory of Religion and Rational Choice Theory. The main conclusion is that, given the specificity of the Economics Theory of Religion, researches that link religion and economics can benefit both disciplines in different ways.
\end{abstract}

Keywords: Religion, economics, market, rational.

* Doutor em Economia Aplicada pelo Programa de Pós Graduação em Economia (PPGE) da Universidade Federal do Rio Grande do Sul (UFRGS). livio@fee.tche.br 


\section{Teoría económica de la religión: Información general}

\section{Resumen}

Este trabajo pretende ser una presentación en general de la teoría económica de la religión. Se utiliza como metodología de la revisión de la literatura sobre este tema. Se presenta el origen y posterior desarrollo de la teoría económica de la religión. Esto demuestra la importancia de la religión desde el punto de vista de la ciencia económica. Se muestra las diferencias entre la teoría económica de la religión y la llamada tesis de la secularización, destacando principalmente la realidad empírica de la persistencia e intensidad del fenómeno religioso. Por último, nos dirigimos a los vínculos entre la teoría económica de la religión y la teoría de la elección racional. La principal conclusión es que, dada la especificidad de la teoría económica de la religión, las investigaciones que articulam la religión y la economía pueden beneficiar las dos disciplinas de diferentes maneras.

Palabras clave: religión, economía, mercado, racional.

\section{Introdução}

Embora muitos pensadores tenham defendido, no passado, a tese de que a religião estaria condenada a desaparecer ${ }^{1}$, atualmente a prática religiosa continua a ser um vetor social de importância preponderante e indissociável da existência da humanidade. Entre esses pensadores que não viam futuro para a prática religiosa em um mundo moderno, dominado pelos valores da ciência, podem ser citados nomes bem conhecidos como o filósofo Auguste Comte $^{2}$ (2000), o sociólogo Émile Durkheim (2001) ou o psicanalista Sigmund Freud (1996).

Conforme Stark, Iannaccone e Finke (1996, p.343-344), esses estudiosos, dentre outros, relacionavam a religião a uma espécie de "mente primitiva", a um processo mental irracional e desinformado. Segundo E. E. Evans-Pritchard (1965, p. 15), os defensores desses pressupostos eram todos agnósticos ou ateístas. Para tais pesquisadores, qualquer tipo de fé religiosa não tinha validade alguma, assim como as religiões primitivas, pois não passavam de meras ilusões. Eram apenas crenças e práticas que poderiam ser qualquer outra coisa, menos razoáveis ou racionais. De acordo com Evans-Pritchard (1965, p.15), o racionalismo desses estudiosos os levava a acreditar que as pessoas eram más e estúpidas porque possuíam instituições ruins. E isto ocorria porque os indivíduos eram ignorantes e supersticiosos devido à exploração religiosa por clérigos espertos e avarentos.

\footnotetext{
Uma das premissas da chamada Tese da Secularização, explicada mais adiante neste trabalho.

2 Comte, que era católico, reconheceu a dificuldade de superar o estágio religioso quando propôs a criação da Religião da Humanidade, onde a própria humanidade seria a Deusa suprema.
} 
Mas, qual o objetivo desses pensadores ao buscar explicar o comportamento religioso tendo como fundamento a teoria da religião primitiva? Evans-Pritchard (1965, p. 15) argumenta: "They sought, and found, in primitive religions a weapon which could, they thought, be used with deadly effect against Christianity". Se as religiões primitivas pudessem ser apresentadas como espécies de aberrações intelectuais, ou como construções arbitrárias baseadas em aspectos emocionais, as demais religiões, mesmo as mais complexas e estruturadas, como o Cristianismo, poderiam ser classificadas de forma idêntica. No entanto, o propósito daqueles intelectuais de exterminar a religião não teve êxito, como prova o persistente interesse de boa parcela dos indivíduos em demandar bens religiosos.

Ainda que a religião seja rechaçada, desacreditada e combatida por muitos indivíduos, notadamente os que professam o ateísmo ou o humanismo, o fato é que os seres humanos, em seu conjunto, de forma generalizada, têm como uma de suas características intrínsecas a adoção e a prática de vários tipos de credos religiosos. Prova disso é a informação da Association of Religion Data Archives (ARDA) de que, segundo dados de 2012, pouco mais de 90\% da população mundial possuía alguma afiliação religiosa ${ }^{3}$. Nessa perspectiva, tendo em vista a importância que possuem as religiões, em nível global, já que estas fornecem bens e serviços tidos como valiosos e desejados pela maioria das pessoas, formando um "mercado religioso", é que surgiu a Teoria Econômica da Religião, denominada também de Economia da Religião (IANNACCONE, 1998). A Teoria Econômica da Religião tem como foco a análise do comportamento religioso, a partir da perspectiva da Teoria da Escolha Racional. Esta considera que a religião é objeto da escolha racional das pessoas no chamado mercado religioso, como sendo um bem ou serviço em outros mercados quaisquer.

No contexto apresentado, este trabalho tem o objetivo de ser uma apresentação, em linhas gerais, da Teoria Econômica da Religião. A metodologia empregada é a revisão bibliográfica. Após esta introdução, a seção um trata da origem e o posterior desenvolvimento da Teoria Econômica da Religião. As conexões entre Teoria Econômica da Religião e a Teoria da Escolha Racional, além das diferenças entre esta e a chamada Tese da Secularização, serão expostas na seção dois. Na seção seguinte será discutida a importância da religião sob a ótica da Ciência Econômica. Por último, serão feitas as considerações finais.

3 Dados obtidos em http://www.thearda.com/internationalData/regions/profiles/Region_23_1.asp. Acesso em: 08 jan. 2016. 


\section{Gênese e desenvolvimento da Teoria Econômica da Religião}

Adam Smith foi o primeiro estudioso a analisar cientificamente as consequências econômicas relacionadas ao grau de concentração do mercado religioso em sua opus magnus A Riqueza das Nações, publicada em 1776. Após duzentos anos, em 1975, Azzi e Ehremberg publicaram o artigo Household Allocation of Time and Church Attendance, considerando o marco de refundação da Teoria Econômica da Religião. A partir deste trabalho de caráter seminal, surgiu, em ritmo crescente, uma sólida pesquisa na área.

Voltando à gênese da Teoria Econômica da Religião, Ekelund, Hebert e Tollinson (2005, p.647) afirmam que o livro V, capítulo I, terceira parte, artigo terceiro do clássico $A$ Riqueza das Nações, de Adam Smith, é uma das partes relativamente mais negligenciadas dessa obra. Foi justamente esse capítulo que lançou as bases para a análise econômica da religião. Nele, Smith adota o conceito de mercado religioso, onde atuam produtores e consumidores de religião, e observa vários aspectos desse mercado. Neste, os clérigos comportam-se de modo idêntico ao de profissionais de outros mercados, tendo como motivação o interesse próprio. $\mathrm{Na}$ análise smithiana, as forças de mercado restringem o comportamento das igrejas de modo semelhante ao que fazem com firmas de outros mercados. No mercado religioso, seja ele dominado por uma firma monopolista ou fundamentada na livre competição, a sua estrutura será determinada pela predominância da regulação ou da liberdade de atuação, de modo idêntico ao que existe para os demais mercados.

Em um período de aproximadamente duzentos anos, compreendido entre o trabalho de Adam Smith (1776) e o artigo de Azzi e Ehrenberg (1975), segundo Oliveira, Cortes e Netto (2011, p.5) a Teoria Econômica da Religião "permaneceu órfã do interesse da grande maioria dos economistas, que preferiram deixar a cargo dos pesquisadores de outras Ciências Sociais, principalmente da Sociologia, a tarefa de examinar os vínculos existentes entre religião e economia". Para Fase (2005, p.90), esses vínculos poderiam ser estudados sob duas abordagens: a perspectiva vertical, enfatizando aspectos institucionais, como igrejas e religiosidade de grupos; e a perspectiva horizontal, concentrando-se em questões como o impacto da religiosidade sobre atitudes específicas que afetariam a sociedade e poderiam promover o crescimento econômico.

Max Weber foi um dos pensadores que enfatizou ambas as perspectivas em seus trabalhos. Em seu livro mais famoso A Ética Protestante 
e o Espírito do Capitalismo (2001), Weber defende a ideia de que a Reforma Protestante contribuiu, decisivamente, para superar os preconceitos medievais contrários à acumulação de riquezas materiais, uma das faces do que ele classifica como "tradicionalismo". Outra categoria conceitual criada por Weber, "o espírito do capitalismo", associado à ética protestante, principalmente a de corte calvinista e puritano, teria, para esse autor, influenciado de modo inequívoco o desenvolvimento econômico dos países onde se verificou a Reforma, como teria sido o caso da Holanda, Suíça e Inglaterra. Esse trabalho de Weber, desde sua publicação, ainda suscita polêmica e calorosos debates.

Tawney (1955), um pesquisador que deu destaque à perspectiva horizontal, por exemplo, conforme observa Fase (2005, p.88), afirmou que, historicamente, as instituições capitalistas mencionadas por Weber são anteriores à Reforma Protestante. Segundo Fase (2005, p.87) Weber e Tawney foram os primeiros estudiosos a dar destaque ao papel da religião na explicação do desenvolvimento econômico. Segundo Oliveira, Cortes e Neto (2011, p.5,6):

Excetuados alguns estudiosos como Weber e Tawney, o estudo da religião foi visto durante muito tempo como antagônico à ciência. Os fatos estilizados da tese da secularização, baseados nos trabalhos de Weber, eram tidos como verdades inquestionáveis. Entretanto esta visão tem se alterado nos últimos anos, permitindo que a Economia da Religião se estabelecesse como disciplina autônoma, além de impulsionar de modo decisivo um novo e crescente interesse de vários estudiosos pelo tema. Muitos pesquisadores, entre os quais sociólogos, cientistas políticos e economistas veem a religião como um elemento importante para entender os desdobramentos históricos, políticos, sociais, e até mesmo como aspecto condicionador das forças econômicas. Compreendendo o comportamento religioso como um caso de escolha racional, esses pesquisadores têm procurado explicar tal comportamento nos níveis individual, de grupo e de mercado.

As pesquisas centradas no nível individual têm procurado explicar os determinantes de participação religiosa (frequência a cultos e doações) e de mobilidade interreligiões e intrarreligiões (troca de denominações e casamento intrarreligioso e interreligioso). As pesquisas voltadas para o nível de grupos têm como meta explicar por que as pessoas aderem a diferentes agrupamentos religiosos. Além disso, esses estudos buscam explicar o porquê de grupos sectários, especificamente, que exigem um alto nível de rigor e de 
compromisso por parte de seus aderentes, terem, em muitos casos, muito sucesso. Por último, as pesquisas relacionadas ao nível de mercado focam o modo como os resultados da estrutura de mercado, seja ela monopolista, de livre competição, regulada ou desregulada se assemelham a outros tipos de mercado. A ciência econômica tende a auxiliar na evolução dos estudos sobre a religião.

Segundo Iannaccone (1998, p.1466) os estudos que relacionam economia e religião podem ser agrupados em três vertentes de pesquisa:

- O enfoque que interpreta o comportamento religioso a partir de uma perspectiva econômica, recorrendo à Teoria Microeconômica e às ferramentas econométricas para explicar padrões de comportamento religioso entre indivíduos, grupos e culturas. Este é o enfoque da Teoria Econômica da Religião ou Economia da Religião;

- A abordagem que privilegia as consequências econômicas da religião;

- A linha de pesquisa que enfatiza os princípios teológicos e escritos sacros para elaborar ou criticar políticas econômicas. Iannaccone chama esta linha de pesquisa de Economia Religiosa, a qual é utilizada, principalmente, por filósofos, teólogos e economistas interessados em analisar as políticas econômicas a partir de uma perspectiva religiosa ${ }^{4}$. Conforme Oliveira, Cortes e Neto (2011, p. 4,5):

É importante também salientar que a Teoria Econômica da Religião é distinta da chamada Economia Religiosa. Enquanto a primeira tem como objetivo a explicação do comportamento religioso humano tendo como base as premissas econômicas, a segunda toma a sua autoridade de escritos sacros, como a Bíblia Sagrada, a Torá e o Alcorão para justificar ou criticar o comportamento econômico. A Economia da Religião, que pode ser compreendida como um empreendimento de cunho positivo, isto é, que procura explicar como o comportamento religioso é e não como deveria ser, transporta princípios da economia para explicar a religião. Por outro lado, a Economia Religiosa, que pode ser entendida como um empreendimento normativo, ao contrário da Economia da Religião, transporta princípios das religiões para explicar a economia e procura mostrar como esta deveria ser com base na interpretação de princípios religiosos. Seus principais estudiosos são filósofos, teólogos e economistas cujo principal interesse é avaliar o impacto de políticas econômicas à luz dos preceitos religiosos.

4 Mangeloja (2003, p. 3) diz que, adicionalmente, existiria uma quarta linha de pesquisa, chamada por ele de teologia econômica. 
A Economia Religiosa engloba os escritos de teólogos, clérigos e economistas ligados ao cristianismo, inclusive aqueles denominados "economistas cristãos", desde os ensinos escolásticos sobre a proibição da usura e a cobrança dos juros até às Encíclicas Papais que fundamentam o pensamento social da Igreja Católica e versam sobre a economia. Entre essas Encíclicas podem ser destacadas aquelas mais antigas, como Rerum Novarum (1891) e Quadragesimo Anno (1931), e as mais recentes como Caritas in Veritate (2009). A Economia Religiosa também inclui pronunciamentos de correntes doutrinárias diversas ligadas ao Protestantismo. Também compreende os trabalhos dos chamados "economistas islâmicos", os quais buscam explicar, justificar ou propor medidas econômicas em áreas como regulação bancária, finanças, impostos e distribuição de renda, tendo como fundamentos o Alcorão, os Hadith (ditos do profeta Maomé) ou os textos da Sunna (IANNACCONE, 1998, p.1466).

Atualmente, o principal expoente da Teoria Econômica da Religião é o economista norte-americano Laurence Iannaccone, da Chapman University, com dezenas de artigos publicados em periódicos como American Economic Review, The Journal of Political Economy, The American Journal of Sociology e The Journal for the Scientific Study of Religion ${ }^{55}$.

A relevância da religião na Economia será tratada na seção seguinte.

\section{Importância da religião na Ciência Econômica.}

A importância da religião para a humanidade é um fato evidenciado pelas estatísticas. O gráfico ${ }^{66}$ a seguir mostra a distribuição da população mundial segundo credos religiosos:

\footnotetext{
5 Para maiores informações ver http://www.chapman.edu/our-faculty/laurence-iannaccone. Acesso em: 03 jul. 2015.

6 Os dados podem ser obtidos em http://www.thearda.com/internationalData/regions/ profiles/Region_23_1.asp. Acesso em: 08 jan. 2016.
} 
Figura 1: Distribuição das religiões no mundo

\title{
Distribuição das religiões no mundo - 2012
}

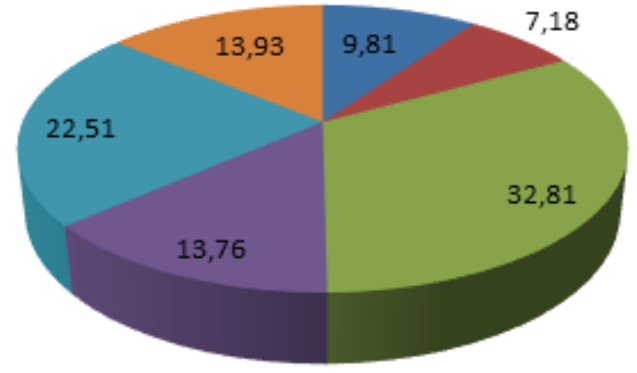

\author{
Agnósticos \\ Budistas \\ n Cristãos \\ Hindus \\ - Muçulmanos \\ Outros
}

Fonte: Association of Religion Data Archives (ARDA).

Como pode ser observado na figura, para dados referentes ao ano de 2012, aproximadamente $90 \%$ da população mundial possuía filiação religiosa, já que o percentual total exclui os agnósticos. Com esses dados em mente, convém lembrar que a religião tem o potencial de influenciar e moldar, de modo decisivo e de diferentes maneiras, o comportamento humano nos aspectos individual e coletivo, contribuindo para a transformação contínua da cultura, da economia e do ambiente de todas as sociedades conhecidas. $\mathrm{Na}$ antiguidade, civilizações floresceram tendo a religião como um de seus pilares fundamentais de sustentação. Segundo o Nobel de Economia de 1993, Douglass North (1990, p.44):

It is simply impossible to make sense out of history (or contemporary economies) without recognizing the central role that subjective preferences play in the context of formal institutional constraints that enable us to express our convictions at zero or very little cost. Ideas, organized ideologies, and even religious zealotry (grifo nosso) play major roles in shaping societies and economies.

Marshall (1996, p.77), grande economista neoclássico, considerou a religião e a economia como as duas instâncias modeladoras mais importantes do comportamento humano ao longo da história: 
Pois o caráter do homem tem sido moldado pelo seu trabalho quotidiano e pelos recursos materiais que busca por esse meio, mais do que por outra influência qualquer, à parte a dos ideais religiosos. Os dois grandes fatores na história do mundo têm sido o religioso e o econômico. Aqui e ali o ardor do espírito militar ou artístico predominou por algum tempo; mas as influências religiosas e econômicas nunca foram deslocadas do primeiro plano, mesmo passageiramente, e quase sempre foram mais importantes do que as outras todas juntas.

Outra afirmação interessante é a de Hull e Bold (1989, p.7):

In light of Stigler's survivorship principle [16], the durability of religion in human societies strongly suggests that churches provide valuable products that aid in the continued survival of the society itself.

O fato de pouco mais de $90 \%$ da população do mundo possuir algum credo religioso, analisado à luz dos argumentos de North (1990), Marshall (1996) e de Hull e Bold (1989), constitui uma justificativa importante para o estudo da Teoria Econômica da Religião e das implicações dela derivadas. Isso porque informa que as religiões fornecem bens e serviços desejados e valiosos para a maioria das pessoas, apesar de toda oposição que as crenças religiosas possam encontrar por parte dos seus críticos.

Considerando as várias crenças religiosas existentes, é interessante constatar que o grau de observância dos fiéis que a elas aderem é muito variado. Enquanto alguns aderentes são extremamente zelosos em obedecer aos preceitos de sua fé, outros não têm o mesmo tipo de empenho e de compromisso. Pelo contrário, sendo a religião um bem que assume a forma de produção coletiva em muitas situações, existe espaço para o surgimento do problema do free-rider, ou carona, comportamento este em que indivíduos procuram apenas obter os benefícios do consumo de bens e dos serviços religiosos sem incorrer em custos.

Também salta aos olhos o fato de, mesmo tendo a possibilidade e a liberdade de praticar determinadas ações que, em princípio, não seriam consideradas condenáveis sob uma ética laica, muitos indivíduos optam por não praticá-las em decorrência da observância da ética religiosa que adotaram. Observando o comportamento humano, depara-se, com muitas situações, de forma rotineira, onde as pessoas que professam alguma religião formam suas preferências e fazem suas escolhas, em um determinado horizonte intertemporal, com base em suas crenças religiosas. 
Por outro lado, preferências moldadas em crenças religiosas também condicionam os seus aderentes a evitar o consumo, de modo temporário ou definitivo, de determinados tipos de bens e de serviços, como bebidas alcoólicas, fumo e literatura obscena. Ou de determinados tipos de alimentos. E isso tem implicações de ordem econômica, no que se refere à influência das religiões na formação de crenças e estruturação das preferências individuais. A questão da formação das preferências é um tópico de interesse da Ciência Econômica, já que esse aspecto comportamental tem impactos na produção, distribuição e consumo de bens e de serviços demandados pela sociedade. Essa também é uma justificativa a ser destacada, pela sua importância, para o estudo da Teoria Econômica da Religião.

Sobre a importância da religião na formação de crenças e preferências individuais, com impactos óbvios sobre o consumo, é pertinente a indagação de Cosgel e Minkler (2004, p.331): "Por que, por exemplo, alguém que nunca provou carne de porco em sua vida consegue formar preferências completas sobre isso?" (tradução minha), referindo-se à abstinência alimentar de carne de porco, praticada por judeus e mulçumanos ${ }^{7}$. Isso acontece, nesse caso, porque existe uma proibição, de caráter religioso, que tem poder coercitivo para os que a aceitam e a ela se submetem, moldando suas preferências.

Assim, quer incentivando o consumo de alguns bens e serviços ou desincentivando o consumo de outros, o que explicaria tal comportamento, que predispõe pessoas em todo o mundo a balizarem suas decisões de consumo de acordo com parâmetros religiosos? O que motivaria boa parte das pessoas a adotar uma determinada religião, utilizando seus recursos escassos, como renda e tempo, para adquirir e consumir bens e serviços religiosos, ofertados no mercado religioso, seja este de livre competição ou regulado pelo governo? Segundo pensadores como Hume (2004), o comportamento religioso seria uma mera expressão de uma mente primitiva do ser humano; ou apenas uma faceta irracional deste, segundo Freud (1996). No entanto, segundo argumentam os teóricos da Escolha Racional ${ }^{8}$, base da Teoria Econômica da Religião, que investigam as relações entre religião e economia, em um corpo crescente de literatura, a prática religiosa pode ser explicada

Diversas outras religiões, além do Judaísmo e do Islamismo, prescrevem dietas alimentares, de caráter temporário ou permanente, aos seus fiéis. Um exemplo é a recomendação de não ingerir carne na sexta-feira de Páscoa feita pela Igreja Católica e de observar outras prescrições dietéticas no período da Quaresma (BROOKS, 2004, p.9).

8 As relações entre Teoria Econômica da Religião e Escolha Racional serão discutidas na próxima seção deste trabalho. 
com fundamentos racionais, inclusive por meio de modelos matemáticos e estatísticos, baseados em evidências que corroboram essas hipóteses, como é o caso do trabalho seminal de Azzi e Ehremberg (1975).

Mesmo aqueles comportamentos impostos, por diversos grupos religiosos, aos seus aderentes, comportamentos esses que poderiam ser, à primeira vista, considerados irracionais, têm, na realidade, uma explicação perfeitamente racional. Exemplos disso são as normas muito rigorosas ligadas ao vestuário e à alimentação. Essas restrições estão ligadas a estratégias de sobrevivência de organizações religiosas que enfrentam o problema do free -rider. Padrões comportamentais religiosos que, durante muito tempo, foram classificados como patológicos e/ou irracionais por muitas pessoas, em geral, e por pesquisadores das Ciências Sociais, em particular, podem ser explicados de forma lógica e coerente pelo arcabouço da Escolha Racional. Isso é possível porque esse tipo de comportamento é parte integrante e fundamental da rationale de organizações religiosas, notadamente as chamadas seitas, em busca de reconhecimento e de conquista de novas fatias do mercado religioso. Sobre essa questão, diz Iannaccone (1994, p.1204):

Rational choice theory thus explains the success of sects, cults, and conservative denominations without recourse to assumptions of irrationality, abnormality, or misinformation.

Essas organizações religiosas adotam estratégias que lhes são típicas: regras de conduta rigorosas, conversões em massa e, geralmente, de forma dramática. Também incluem alto nível de compromisso religioso, pregação de milagres e exorcismos, rejeição a mudanças sociais, apelos a minorias, dentre outras. Igrejas reconhecidas e seitas extremistas, sob esse ângulo, aparecem como categorias analíticas existentes no mercado religioso, e não como sendo explicações ad hoc descritivas de um fenômeno religioso, conforme observa Iannaccone (1994, p.1204).

Na próxima seção serão discutidas as conexões entre Teoria Econômica da Religião e Teoria da Escolha Racional.

\section{Teoria Econômica da Religião e Escolha Racional}

A Teoria Econômica da Religião tem como um dos suportes teóricos os trabalhos seminais de Gary Becker (1965) relacionados ao Modelo de Produção Doméstica e alicerçados na chamada Teoria da Escolha Racional. 
Becker, no livro Economic Approach To Human Behavior (1976, p.14), afirma que "the economic approach provides a useful framework for understanding all human behavior". Por outro lado, afirmações como essas têm sido interpretadas por estudiosos e pesquisadores de outras áreas das Ciências Sociais como uma espécie de "imperialismo econômico" ". Sobre essa questão, afirma Lazear (2000, p.99):

Economics is not only a social science, it is a genuine science. Like the physical sciences, economics uses a methodology that produces refutable implications and tests these implications using solid statistical techniques. In particular, economics stresses three factors that distinguish it from other social sciences. Economists use the construct of rational individuals who engage in maximizing behavior. Economic models adhere strictly to the importance of equilibrium as part of any theory. Finally, a focus on efficiency leads economists to ask questions that other social sciences ignore. These ingredients have allowed economics to invade intellectual territory that was previously deemed to be outside the discipline's realm.

São diversas as polêmicas suscitadas pela chamada "invasão" da Ciência Econômica em territórios de pesquisa antes restritos a outras Ciências Sociais, como é o caso da religião. Mas o objetivo deste trabalho não é debater nem se aprofundar nessa polêmica. O fato a ser ressaltado é que o enfoque específico da Teoria Econômica da Religião tem como core (cerne, núcleo) a análise do comportamento religioso, com fundamentos microeconômicos, formulados pela Teoria da Escolha Racional, em um contexto de mercado, no que concerne à prática religiosa de indivíduos, grupos e coletividades em geral (regiões, nações, continentes, etc.). A escolha racional pode ser definida como aquela que maximiza a utilidade de um indivíduo. O comportamento religioso pode ser definido como sendo um conjunto de atitudes e de práticas oriundas de crenças religiosas, para atingir determinados objetivos, sejam de caráter natural ou supranatural.

As três premissas básicas da Teoria da Escolha Racional são: comportamento maximizador de utilidade, estabilidade nas preferências e equilíbrio do mercado religioso (BECKER, 1976). Das três premissas, a da maximização da utilidade é a principal (IANNACCONE, 1995, p.77) e se aplica tanto ao consumidor como ao produtor no mercado religioso. Os produtores religiosos

9 Isso é demonstrado, por exemplo, pelo título de um livro de Radnitzky e Berholz (1986): Economic Imperialism: The Economic Method Applied Outside the Field of Economics. 
são maximizadores de utilidade no que se refere ao número de fiéis, do apoio governamental e de outros determinantes institucionais que sejam necessários ao sucesso das organizações religiosas (IANNACCONE, 1995, p. 77).

Um dos conceitos basilares da Teoria Econômica da Religião é o de commodity religiosa. Este termo, segundo Iannaccone (1992a, p.124), identifica a religião como um objeto de escolha, incluindo bens e serviços religiosos que podem ser produzidos e consumidos pelos agentes atuantes no mercado religioso.

Quando se faz referência aqui ao mercado religioso e a bens religiosos, como sendo mercadorias ou commodities religiosas, pessoas com sensibilidade religiosa poderiam ser levadas a ver nisso uma espécie de dessacralização ou desrespeito a algo considerado transcendental como a religião. No entanto, não há, de modo algum, nos pressupostos da Teoria Econômica da Religião, nenhum tipo de tentativa deliberada e propositada de nivelar as religiões ao patamar de meras trocas monetárias, um esforço de reificação ou ainda uma mera mercantilização da fé por parte da Ciência Econômica.

Conforme diz Iannaccone (1992a, p.123) não é disso que se trata. Quando se diz que, no mercado religioso, do lado da demanda, consumidores procuram ponderar benefícios e custos para maximizar sua utilidade, e do lado da oferta, produtores buscam produzir bens e serviços religiosos de forma tão competitiva quanto seus concorrentes a fim de conquistar fiéis, não há nenhuma intenção de reduzir-se as categorias religiosas à trivialidade. Não se está dizendo que as pessoas trocam de religião como quem troca de roupa ou que as pessoas vão à igreja, à mesquita ou à sinagoga como quem vai ao shopping center, apenas para comprar, passear ou divertir-se. Isso seria uma percepção simplista, grosseira e equivocada.

O que se deve ter em mente é que o emprego da terminologia econômica ao estudo científico da religião tem amplas vantagens. Entre essas vantagens podem ser citadas o poder de concisão, de integração, de abrangência e de explicação da Ciência Econômica, mais precisamente como no caso em que emprega a metodologia da Teoria da Escolha Racional. Esta teoria passou a firmar-se como um novo paradigma no estudo científico da religião, no contexto das Ciências Sociais e, por outro lado, tornando-se a pedra angular de uma nova disciplina: a Teoria Econômica da Religião. A Teoria da Escolha Racional pretende, aplicando seus pressupostos, modelar as mudanças comportamentais, observadas nas ações humanas, como estratégias ótimas de resposta a alterações nas restrições enfrentadas pelo ser humano, como, por exemplo, de preço e de renda. 
A Teoria da Escolha Racional não afirma que todas as pessoas são absolutamente racionais e agem sempre racionalmente, logicamente ou apenas tendo em vista seu auto-interesse (IANNACCONE, 2006, p.24). Apenas afirma que os bens e serviços religiosos são objetos de escolha dos indivíduos, como seriam outros tipos de bens e serviços não religiosos, conforme observa Iannaccone (1992b, p.272). Nesse sentido, a racionalidade é uma premissa simplificadora (IANNACCONE, 2006, p.24). Os consumidores religiosos comparam custos e benefícios resultantes da escolha religiosa, a fim de maximizar os benefícios líquidos oriundos dessa escolha, a qual também não é imutável, pois que também as opções religiosas e o nível de compromisso religioso podem ser modificados ao longo do tempo.

No próximo tópico serão esclarecidas algumas questões sobre a chamada Tese da Secularização e a Escolha Racional.

\subsection{Tese da secularização e Escolha racional}

Stark, Iannaccone e Finke (1996, p.433), observam que alguns fatos estilizados relacionados à religião, defendidos pela Tese (ou teoria para os defensores desta) da Secularização ${ }^{10}$ - onde um de seus maiores representantes seria Max Weber (2001) e tidos anteriormente como inquestionáveis, foram sendo desmentidos com o passar do tempo. Esses fatos estilizados sustentavam as seguintes premissas:

i) O declínio da religião com o avanço da ciência e do progresso tecnológico;

ii) $\mathrm{O}$ decréscimo da religiosidade e o aumento do ceticismo à medida que os indivíduos se tornassem mais educados e mais familiarizados com a ciência;

iii) A prática religiosa seria resultado de doutrinação, conduzindo a valores distorcidos; ou de anormalidades psicológicas como neurose, trauma ou de necessidades não-satisfeitas.

Além disso, Stark, Iannaccone e Finke (1996, p.436) e Stark (2002, p.193-195), baseados em pesquisas quantitativas, afirmam que a Tese da Secularização encontra mais apoio apenas entre profissionais das chamadas Ciências Humanas e Sociais, como antropólogos, psicólogos e, em menor extensão, sociólogos. Já pesquisadores ligados às Ciências Exatas, como físi-

10 Pierucci (1998, p.10) questiona os autores que consideram Max Weber como o autor ou o principal representante da Tese da Secularização. 
cos e químicos tenderiam, em maior proporção, a professar uma fé religiosa e a frequentar cultos religiosos. A tabela 1 representa os dados referentes à religiosidade de 60.028 acadêmicos norte-americanos (um quarto do total do universo de acadêmicos dos EUA à época), baseados numa pesquisa realizada em 1969 pela Carnegie Commission.

Tabela 1 - Religiosidade por Área Científica nos EUA

\begin{tabular}{|c|c|c|c|}
\hline \multirow[b]{2}{*}{ Área } & \multicolumn{3}{|c|}{ Percentagem } \\
\hline & $\begin{array}{c}\mathbf{E} \\
\text { religioso }\end{array}$ & $\begin{array}{c}\text { Frequenta } \\
\text { regularmente }\end{array}$ & Opõe-se à religião \\
\hline Matemática e Estatística & 60 & 47 & 11 \\
\hline Física & 55 & 43 & 11 \\
\hline Ciências Biológicas & 55 & 42 & 11 \\
\hline Ciências Sociais & 45 & 31 & 13 \\
\hline Economia & 50 & 38 & 10 \\
\hline Ciência Política & 51 & 32 & 10 \\
\hline Sociologia & 49 & 38 & 12 \\
\hline Psicologia & 33 & 20 & 21 \\
\hline Antropologia & 29 & 15 & 19 \\
\hline
\end{tabular}

Fonte: Stark (2003)

A pesquisa incluía perguntas relacionadas a questões acadêmicas e atitudes sócio-políticas, além de questões religiosas, como: "Quantas vezes você frequenta serviços religiosos?", "Qual a sua religião atual?", "O quanto você se considera religioso?" e "Você se considera um religioso conservador?". Esta pesquisa é considerada a mais abrangente do gênero realizada até hoje, segundo Stark (2003, p. 194). Este chama a atenção para dois resultados particularmente interessantes quanto à propalada incompatibilidade, formulada pela Tese da Secularização, entre religião e ciência: a) os níveis relativamente altos de religiosidades dos acadêmicos norte-americanos, à época em que foi realizada a pesquisa, e b) o maior nível de religiosidade dos acadêmicos das áreas cientificamente mais maduras, como as de exatas, em relação aqueles profissionais ligados a áreas científicas mais recentes, como a de Ciências Humanas. 
Ainda conforme Stark (2003), talvez o resultado mais notável é que nas áreas ligadas à "Hard Science" os entrevistados tendem a frequentar mais serviços religiosos, a se declararem como "profundamente" ou "moderadamente" religiosos e ter filiação religiosa. Os resultados se mantêm mesmo após serem realizados testes com variáveis de controle, como gênero, grupo étnico, idade e educação religiosa. Outras pesquisas, de acordo com Stark (2003), também apontam para o fato de que os cientistas sociais ligados ao que se chama de "Soft Science", identificados como aqueles que tenderiam a ter um menor grau de religiosidade, relativamente a seus pares das áreas de Exatas, já apresentavam tal comportamento, antes de ingressarem em seus respectivos cursos superiores ou de pós-graduação.

Uma das explicações para esse fenômeno seria, dentre outras, de acordo com Stark, Iannaccone e Finke (1996), a hipótese de que antropólogos e psicólogos seriam irreligiosos porque discutiriam extensamente sobre religião. Por outro lado, pesquisadores da Hard Science permaneceriam ignorantes sobre as contradições das religiões. Mas, essa explicação não considera que físicos discutem intensamente sobre as origens do universo e biólogos debatem vastamente sobre a evolução das espécies, o que envolveria, de um modo ou de outro, questões religiosas. Stark, Iannaccone e Finke (1996) levantam a hipótese de que a rejeição da esfera religiosa por cientistas da Soft Science, como antropólogos e psicólogos, teria algo a ver com a existência de afirmações não testáveis, isto é, não falseáveis e não verificáveis, segundo os critérios de Popper, em suas respectivas disciplinas. Isso as colocaria em competição direta com as religiões, as quais, também, se baseiam em afirmações não sujeitas aos critérios científicos de falseabilidade e de verificabilidade.

Tendo os resultados dessa pesquisa em mente, percebe-se que, diferentemente do que afirmam os fatos estilizados da Tese da Secularização, mesmo com a ciência progredindo a passos largos, o avanço tecnológico se acelerando e o nível médio de escolaridade aumentando em diversos países, a religiosidade não arrefeceu. O que se observa é justamente o contrário em muitas regiões e países do mundo. Iannaccone (1998, p. 1468-1469) cita o caso dos EUA. Este país é representativo, pois que concentra grande parte do avanço científico e tecnológico em nível mundial. Baseado em pesquisas de opinião pública de nível nacional nos EUA, Iannaccone (1998, p. 14681469) enumera várias evidências que não dão apoio àqueles fatos estilizados, citados anteriormente, da Tese da Secularização. 
Segundo Oliveira, Cortes e Neto (2011), ao contrário da Tese da Secularização, a qual sustenta que mudanças religiosas são respostas a variações na demanda, como consequência das alterações nos gostos, preferências, tendências histórico-culturais, a Teoria da Escolha Racional advoga uma tese antagônica. Isto é, que as mudanças religiosas têm como origem as variações no lado da oferta religiosa. Tais variações estariam conectadas, essencialmente, ao nível de intervenção governamental no mercado religioso. Esse nível de intervenção estatal teria impactos no grau de pluralismo e de competição observado no mercado religioso. Por outro lado, a demanda dos consumidores, na perspectiva da Escolha Racional, teria como característica preferências religiosas estáveis. Neste contexto, a Escolha Racional reposicionou o foco do estudo científico da religião, nas Ciências Sociais, do lado da demanda para o lado da oferta religiosa. Por esse fato, passou a ser denominada de "Novo Paradigma" (Warner, 1993).

\section{Considerações finais}

Conforme foi mostrado anteriormente, a grande maioria da população do mundo pratica algum tipo de religião, o que, por si só, já é um motivo para justificar o estudo do mercado religioso. Este é um espaço extremamente diversificado, onde existe uma gama variada de ofertas de bens, ou commodities religiosas, competindo pelos recursos escassos de consumidores e de outros potenciais consumidores. As estratégias utilizadas pelas religiões para angariar novos adeptos, ou simplesmente manter os já existentes, também estão inseridas num espectro muito amplo, podendo ir de métodos pacíficos, como a simples persuasão e inovação religiosa, ou mesmo violentos, como conversões forçadas. Diferentemente do que ocorre em outros tipos de mercados, no mercado religioso a competição por conquista de espaços pode resultar, como tem acontecido no decorrer da história, no aniquilamento físico de aderentes pertencentes a organizações religiosas rivais, ou mesmo de aderentes com comportamentos classificados como desviantes ou "heréticos".

No aspecto relacionado a questões econômicas, existem credos religiosos que desautorizam o envolvimento de seus aderentes com assuntos de cunho material, enquanto outros incentivam seus fiéis a serem ativos na busca de riquezas. E tudo isso, obviamente, tem implicações fundamentais na questão das escolhas religiosas, bem como na formação das preferências e das crenças individuais, tópico de particular interesse da Economia na explicação da racionalidade econômica do ser humano. 
Para Iannaccone (1998, p.1465), os estudos que relacionam religião e economia podem beneficiar ambas as disciplinas de diversas formas: gerando informação sobre comportamento extra-mercado; revelando como modelos econômicos podem ser modificados para avaliar questões a respeito de crenças, normas e valores; explicando as características das organizações religiosas, suas hierarquias e incentivos; além de permitir investigar como a religião (e extensivamente a moral e a cultura, já que a religião está intrinsecamente associada a estas) influencia as atitudes e as atividades econômicas de indivíduos, de grupos e de sociedades.

O estudo científico da religião, antes do advento do novo paradigma da Teoria da Escolha Racional, esteve fundamentado secularmente na Tese da Secularização, a qual passou a enfrentar uma forte concorrência. A Escolha Racional tem a seu favor o seu rigor lógico teórico e alto nível de formalização no estabelecimento de premissas preditivas com ampla possibilidade de testes empíricos. Estes poderiam ser aplicados a diversas questões, incluindo escolha, nível de participação e mudança religiosas; estrutura do mercado religioso; igrejas, seitas e cultos; comportamentos religiosos desviantes; estratégias de expansão de organizações religiosas; impactos da intervenção governamental no mercado religioso sobre o bem-estar dos agentes econômicos, dentre outros temas estudados, permitindo a interação entre a pesquisa religiosa e os estudos sobre instituições "non-markeet".

\section{Referências}

AZZI, C.; G. Ehrenberg, R. Household allocation of time and church attendance. Journal of Political Economy, v. 83, n.1, p. 27-56, 1975.

BECKER, G. S. A Theory Allocation of Time. Economic Journal, v.75, n. 299, p. 493-517, 1965.

BECKER, G. S. The Economic Approach To Human Behavior. Chicago: University Chicago Press, 1976.

BROOKS, N. Overview of Religions. Clinical Cornestone [online] ,v.6, n.1, p.7-16, 2004.

COMTE, Auguste. The Positive Philosophy. Ontário: Batoche Books, 2000.

COSGEL, M. M.; MINKLER. L. Rationality, Integrity, and Religious Behaviour. Journal of Socio-Economics, v.33, n.3, p. 329-341, 2004.

DURKHEIM, É. As Formas Elementares da Vida Religiosa. São Paulo: Editora Paulus, 2001.

EKELUND, R. B.; Jr.HEBERT, R. F.; TOLLINSON, R. D. Adam Smith on Religion and Market Structure. History of Political Economy, v.37, n.4, p. 647-660, 2005. 
EVANS-PRITCHARD, E.E. Theories of Primitive Religion. Londres: Oxford University Press, 1965.

FASE, M. M. G. On Economics and Religions. The Economist, v. 153, p. 85-106, 2005.

FREUD, S. O Futuro de uma Ilusão, o Mal-Estar na Civilização e outros trabalhos (1927-1931). Rio de Janeiro: Editora Imago, 1966.

ELLINSON, C.G. Religious Involvement and Subjective Well-Being. Journal of Health and Social Behavior, v.32, n.1, p. 80-99, 1991.

ELLINSON, C. G.The Religion-Health Connection: Evidence, Theory, and Future Directions. Health Education \& Behavior, v.25, n.6, p.700-720, 1998a.

ELLINSON, C.G. Introduction to Symposium: Religion, Health, and Well-Being. Journal for the Scientific Study of Religion, v.37, n.4, p.692-694, 1998 b.

EVANS-PRITCHARD, E.E., Theories of Primitive Religion, Oxford University Press, 1965.

HULL, B.B; BOLD, F. Towards an Economic Theory of the Church. International Journals of Social Economics, v.16, n.7, p. 5-15, 1989.

HUME, D. História Natural da Religião. São Paulo: Editora Unesp, 2004.

IANNACCONE, L. Religious Markets and the Economics of Religion. Social Compass, v.39, n.1, p.123-131, 1992a.

IANNACCONE, L. Sacrifice and Stigma: Reducing Free-riding in Cults, Communes, and Other Collectives. The Journal of Political Economy, v.100, n.2, p.271-291, 1992 b.

IANNACCONE, L.Why Strict Churches Are Strong. The American Journal of Sociology, v.99, n.5, p.1180-1211, 1994.

IANNACCONE, L. Voodoo Economics? Reviewing the Rational Choice Approach to Religion. Journal for the Scientific Study of Religion, v.34, n.1, p. 76-89, 1995.

IANNACCONE, L. Introduction to the Economics of Religion. Journal of Economic Literature, v. 36, n.3, p.1465-1496, 1998.

IANNACCONE, L. Economy, in Helen R. Ebaugh (Ed.). Handbook on Religion and Social Institutions, Plenum Press, p. 21-39, 2006.

IANNACCONE, L; STARK, R; FINKE, R. Rationality and the Religious Mind. Economic Inquiry, v.36, n.3, p.373-389, 1998.

INSTITUTO DATA FOLHA. 90\% dos brasileiros vão à igreja, a cultos ou serviços religiosos 17\% frequentam mais de uma religião. Disponível em: http://media.folha.uol.com.br/datafolha/2013/05/02/religiao_03052007_1.pdf. Acesso em: 08 jan. 2015.

LARGEST RELIGIOUS GROUPS (THE WORLD).ARDA - Association Of Religion Data Archive. Disponível em: http://www.thearda.com/internationalData/regions/profiles/ Region_23_1.asp. Acesso em: 08 jan. 2016.

LAZEAR, E. Economic Imperialism. Quarterly Journal of Economics, v. 115, n.1, p. 99$146,2000$. 


\section{Livio Luiz Soares Oliveira Correio}

MANGELOJA, E. Implications of the Economic of Religion to the Empirical Economic Research, University of Jiväskylä, School of Business and Economics, 2003. Disponível em: http:// citeseerx.ist.psu.edu/viewdoc/download?doi=10.1.1.198.2689\&rep=rep1\&type=pdf . Acesso em: 08 jan. 2015

MARSHALL, Alfred. Princípios de Economia. São Paulo: Editora Nova Cultural Ltda, 1996.

OLIVEIRA, L.L.S; CORTES, R.X; BALBINOTTO NETO, G. A economia da religião e seus fundamentos: teste de um modelo de escolha religiosa. Estudos Econômicos [online], v. 41, n.4, p. 811-840, 2011. Disponível em: http://www.scielo.br/scielo.php?script=sci_arttext\&pi$\mathrm{d}=$ S0101-41612011000400006\&lng=en\&nrm=iso. Acesso em: 08 jan. 2015.

PIERRUCI, A. Secularização em Max Weber: Da contemporânea serventia de voltarmos a acessar aquele velho sentido. Revista Brasileira de Ciências Sociais [online], v. 13, n. 37, p. 43-73, 1998. . Disponível em: http://www.scielo.br/scielo.php?script=sci_arttext\&pid =S0102-69091998000200003. Acesso em: 06 jul. 2015

RADNITZKY, G.; BERHOLZ, P. Economic Imperialism: The Economic Method Applied Outside the Field of Economics. New York: Paragon, 1986.

ROMERO, César Jacob, et alii. Atlas da Filiação Religiosa e dos Indicadores Sociais no Brasil. São Paulo: Edições Loyola, 2003.

SMITH, Adam. Riqueza das Nações: Uma Investigação Sobre Suas Naturezas e Suas Causas. São Paulo: Editora Nova Cultural Ltda, 1996.

STARK, R.; IANACONNE, L.R.; FINKE, R. Religion, Science and Rationality. The American Economic Review, v.86, n.2, p.433-437, 1996.

STARK, R. For the Glory of God: How Monotheism led to Reformation, Science, Witch -Hunts and the End of Slavery. Princenton: Princenton University Press, 2003.

TAWNEY, R. H. Religion and the Rise of Capitalism. EUA: Mentor Books, 1955.

WARNER, Stephen. Work in progress toward a new paradigm for the sociological study of religion in the United States. American Journal of Sociology, v. 98, n. 5, p. 1044-1093, 1993.

WEBER, Max. A Ética Protestante e o Espírito do Capitalismo. São Paulo: Editora Martin Claret, 2001.

Submetido em: 28-6-2016

Aceito em: 24-4-2017 